\title{
25 The political work of waste picker integration
}

\author{
Melanie Samson
}

Historically, reclaimers who informally collect reusable and recyclable materials were as ignored by academics as they were by policy-makers. Although there is now burgeoning interest in the people both groups tend to refer to as "waste pickers", these interests are running in different directions. Key areas of focus in scholarly research include the role of waste pickers in the production of value, their relation to the global economy, their environmental contributions, how they are dispossessed by municipal recycling contracts, and how they are organising. For their part, policy-makers at levels ranging from local government to the World Bank focus their attention on promoting and implementing waste picker integration as part of a broader trend towards "formalising the informal economy". While there is a large and growing policy-oriented literature on waste picker integration, curiously scant attention has been paid to this global policy trend in academic debates.

Yet waste picker integration is far from just a technical policy issue. In this chapter I argue that the concept of waste picker integration performs important political work. ${ }^{1}$ The chapter further contends that critically interrogating this political work is both theoretically generative and relevant to the struggles of reclaimer movements. In the chapter I refer to waste picker integration when this concept is used, but refer to the workers as reclaimers. "Reclaimer" emphasises that these workers are rescuing items with potential value from being wasted and engaging in multiple, complex forms of labour to revalue them, while "waste picker" associates them with rubbish and reduces their work to the simple act of "picking".

The remainder of the chapter is divided into three sections. The first section presents four key ways waste picker integration is conceptualised in the literature. The second section identifies the erasures that underpin these conceptualisations and the political work that they perform. The concluding section explores the transformative political work that is possible when focus is shifted from waste picker integration to the integration of municipalities and industry into the existing recyclingscape ${ }^{2}$ established by reclaimers.

\section{Conceptualisations of integration}

Kashyap and Visvanathan (2014) note that the term "integration" encompasses a wide range of policies and programmes. This can be attributed, at least partially, 
to the fact that most literature on waste picker integration is policy-oriented. Although authors generally do not define what they mean by integration, I argue that it is possible to discern four different conceptualisations of waste picker integration.

\section{Conceptualisation 1: waste picker integration as charity}

The first strand of literature implicitly frames waste picker integration as a charitable activity conducted by local government or industry for waste pickers to assist them in purportedly marginal, survivalist work. Velis et al. (2012: 60) refer to projects rooted in this understanding as "traditional development approaches to integration" that "focus on 'helping' waste pickers" without recognising them as partners or even consulting them. Such projects typically include the provision of training, equipment and space. They can also include initiatives designed by local government and/or industry to encourage waste pickers to form companies and cooperatives that become the recipients of support and contracts. The four key aspects of this conceptualisation are: (1) integration focuses narrowly on the daily physical work of extracting, sorting, cleaning and selling materials; (2) integration programmes provide support to directly assist waste pickers in conducting their work; (3) programmes focus on the integration of waste pickers' labour, rather than integration of their recycling system; and (4) waste pickers are passive targets of local government programmes. Unsurprisingly, waste pickers frequently do not want to be integrated in the ways envisioned by government and industry, leading to project failure and adverse effects for the very reclaimers the projects claim to be assisting (Ahmed and Ali 2004; Scheinberg 2012; Velis et al. 2012; Reddy 2015; Pholoto 2016; Sekhwela 2017).

\section{Conceptualisation 2: waste picker integration as participation}

The second conceptualisation continues to frame waste picker integration as integration of reclaimers' daily labour to improve their livelihoods. However, policies and programmes are developed through participatory approaches (which range from tokenistic to democratic), as policy-makers, donor agencies and academics increasingly recognise that successful integration requires the active involvement of reclaimers (Nas and Jaffe 2004; Nzeadibe and Anyadike 2012; Scheinberg 2012; Velis et al. 2012; Ezeah, Fazakerley and Roberts 2013). In order to facilitate meaningful participation, support is often provided to waste pickers to form and sustain organisations to represent themselves (Gunsilius 2012; Velis et al. 2012; Masood and Barlow 2013). This approach can also include attention to the specific histories, politics and other key aspects of different places in order to identify the most relevant ways to integrate the work of waste pickers in a particular context. 


\section{Conceptualisation 3: waste picker integration as a multifaceted process}

The third conceptualisation also emphasises the importance of participation in the integration of reclaimers' daily work. However, in this approach, waste picker integration is conceptualised as a multifaceted process that requires social, cultural, political, legal and economic interventions, as each of these spheres shapes waste pickers' work (Dias 2011c; Gunsilius 2012; Scheinberg 2012; Ezeah, Fazakerley and Roberts 2013). Due to the stigmatisation of reclaimers, strong emphasis is placed on social and cultural interventions to generate the recognition of and respect for reclaimers required for them to perform their work unhindered (Nas and Jaffe 2004; Nzeadibe and Anyadike 2012; Velis et al. 2012; Masood and Barlow 2013; Cohen 2014).

\section{Conceptualisation 4: waste picker integration as social transformation}

The fourth conceptualisation moves beyond utilitarian integration into other spheres. Rather than being an end in itself, waste picker integration is conceptualised as part of larger political projects and struggles for social justice and transformation (Gutberlet 2008; Chikarmane 2012). Dias (2011c) argues that the process of developing waste picker integration policies and programmes is as important as the policies and programmes themselves, as it forges new forms of citizenship. Chikarmane and Narayan (2005) highlight how in organising around integration, reclaimers transform their understanding of the world and their place within it. Integration therefore becomes one way of changing these current oppressive and exclusionary realities. While this conceptualisation of integration is held primarily by reclaimer organisations, to a certain extent, it also underpinned the policies and programmes of the Workers' Party (PT) as well as local and national governments in Brazil (Gutberlet 2008; Dias 2011a).

\section{Integration as erasure}

When looking at the political work of integration, it is useful to think about waste picker integration as erasure. As the narrowest form of integration, waste picker integration as charity is based on five key erasures. The first is the erasure of reclaiming as a productive economic activity. This strips reclaimers of their identities as workers who make important economic contributions, and enables the state and industry to treat reclaimers as the fortunate recipients of municipal beneficence. In doing so, the state and industry relieve themselves of the responsibilities to do the following:

- remunerate reclaimers for the services they provide;

- $\quad$ ensure a fairer distribution of profits in the sector;

- $\quad$ support reclaimers in transforming their place in the recycling value chain; 
- $\quad$ even give reclaimers preference over poor community members when jobs are created in formal recycling programmes.

Second is the erasure of reclaimers' knowledge. Before reclaimers can even start to think of reaching their hands into rubbish bins, they must reject the municipality's understanding of domestic waste as anything disposed of by residents, and develop a more refined ontology that differentiates potential value from waste. They then need to develop a deep understanding of the nature of the different materials they salvage and the differing potential values congealed within them. Other essential types of knowledge include knowledge of the patterns and rhythms of waste collection in the city; and how to categorise and prepare materials for sale; and the recycling market and its local geographies. By erasing the epistemic agency of reclaimers, municipalities and industry reduce reclaimers to unthinking manual labourers who do not possess valuable insights into how the recycling system in the city does and should function. Municipalities and industry are therefore able to justify denying reclaimers" "epistemic participation" (Fricker 2010; Hookway 2010) in both the development of municipal separation at source programmes and, ironically, in the design of "integration" programmes.

Third, just as colonialists cast colonised land as barren, wasted, and lying in wait to be put to productive use in their own interests (McClintock 1995; Gidwani 2008; Goldstein 2013), municipalities and industry erase the "recyclingscape" created by the reclaimers. Due to their unwillingness to recognise this informally produced system, municipalities and industry see only a "wastescape", which conveniently enables them to deem themselves the best custodians of the space and midwives of a completely new recyclingscape.

The fourth erasure is the erasure of reclaimers' forging of a new sphere of accumulation (Samson 2015b). Reclaimers created the recyclable collection system in virtually all post-colonial cities. As municipalities treated recyclable materials as trash that needed to be collected, transported and landfilled, recyclables put out for collection were a cost to the municipality. It was reclaimers who identified that value could be extracted from items misclassified as waste. In doing so, they informally created a new sphere of accumulation. By denying its existence, municipalities and industry can enclose the recyclables commons in a process of accumulation by dispossession (ibid.), claim to be creating a completely new sphere of accumulation, and avoid paying compensation to the reclaimers who are dispossessed.

The final erasure is the erasure of reclaimers' very humanity. The rendering of reclaimers as "human waste" (Bauman 2004) has been documented in cities across the world (Nas and Jaffe 2004; Gidwani and Reddy 2011). Understanding that reclaimers are framed as "surplus people" living at the very edges of the economy and society helps to explain why municipalities feel that they do not need to pay reclaimers for the service they provide, include them in the setting of priorities and decision-making, or consider how they are affected by separation at source. 
Taken together, these five erasures consolidate existing power relations; dispossess reclaimers; exacerbate their political, social, epistemic and economic marginalisation; and open new spheres of accumulation for capital and patronage for the local state.

While these erasures are most fully realised in the conceptualisation of waste picker integration as charity, to varying degrees they also underpin conceptualisations 2 and 3 of waste picker integration as "participation" and "multifaceted". Although these two conceptualisations recognise reclaimers' work and knowledge, both are highly circumscribed; the work that is acknowledged is limited to the daily labour of reclaiming, and reclaimers' knowledge is drawn on in a utilitarian way in order to design better projects and programmes to integrate this daily work. Reclaimers are not completely dismissed as human waste, but they are also not considered and engaged as complex, multidimensional people involved in all spheres of social, political and economic life. Their role in creating a new sphere of accumulation, and the very existence of that sphere remain erased.

For the most part, projects rooted in conceptualisations 2 and 3 do not recognise the reclaimers' recyclingscape and focus instead on integrating individual reclaimers and cooperatives. Even when the recyclingscape is recognised, it is assumed that it should be integrated with the municipality's envisioned recyclingscape or be kept in mind when reclaimers and the municipality collectively design a new one. The existing recyclingscape is not given primacy as the foundation for any new developments, and at best reclaimers are treated as equal partners in these processes rather than leading them.

\section{Municipal and industry integration into the reclaimers' recyclingscape}

Just as the meaning of "integration" in waste picker integration has been insufficiently theorised, the assumption that it is waste pickers who are being integrated also needs to be problematised. Reclaimer Louis Mahlangu dismissed this notion when he informed industry representatives and national and local officials in a meeting that "it is the city who is integrating itself on our existing structures, because we've been doing it for many years, so it is them who is integrating onto our existing system."

Rather than looking at how to include reclaimers in formal waste management and recycling systems, the real question is how municipal and industry systems should integrate into the reclaimers' recyclingscape. This approach redresses the "erasures" of waste picker integration as it recognises reclaimers as human beings engaged in all spheres of life; epistemic agents; workers with rights to the materials they collect; and creators of the recyclingscape and a new sphere of accumulation. As in Latin America, where the people who perform this labour and their organisations use names that associate them with recycling and the collection of valuable materials, the use of the word reclaimer (rather than waste picker) removes the association of reclaimers with the rubbish 
residents mix their recyclables into, and focuses instead on reclaimers' creative act of imbuing these trashed recyclables with new value.

Understanding integration as the integration of municipal and industry systems into the reclaimers' recyclingscape performs important broader transformative political work. It expands the ontology of the economy not merely to include the informal economy, but also to recognise that activities defined as informal often serve as the base for integrated economic processes. It also disrupts established understandings of who has knowledge and expertise, how knowledge is generated, and whose perspectives and ideas are crucial for political and economic processes. In doing so, this conceptualisation demands transformations in forms of governance and in the social, political, economic and cultural spheres.

This conceptualisation of integration as integration into reclaimers' recyclingscape shares many affinities with "integration as transformation". In this regard, it is important to note that the Portuguese literature about Brazil uses the term "inclusive recycling", and this is typically carried through into English language articles written about Brazil (cf. Gutberlet 2008; Dias 2011d). While this moves away from the notion that it is waste pickers who must be integrated, the term "inclusive recycling" conveys notions of equality between the parties. By contrast, redressing the erasures of integration makes clear that reclaimers, the recyclingscape they produced and reproduce on a daily basis, and the sphere of accumulation they created should be given primacy. It therefore more clearly articulates and redresses the existing unequal power dynamics in how municipalities and industry relate to reclaimers.

Of course, it is one thing to call for a transformation in power relations and another to actually achieve this. As movements of reclaimers, formal and informal workers, and all oppressed and exploited groups know all too well, those with power do not readily relinquish it. However, focusing on identifying and reversing these and other erasures of integration can hopefully assist reclaimer movements in developing and bolstering deeper demands and more expansive visions of the future.

\section{Acknowledgements}

The research for this chapter was funded by the South African Department of Science and Technology through the Waste Research, Development and Innovation Roadmap.

\section{Notes}

1 Here I am drawing on Stuart Hall's (2008) theorisation of the "political work" that race does.

2 Swyngedouw's (1999) concept of the "waterscape" had inspired some waste and discard scholars to begin to use the term "wastescape". I argue that it is crucially important to see the "recyclingscape" forged by reclaimers and to understand that this is the terrain on which all debates about municipal and industry recycling programmes play out. 